\title{
Dermal Fibroma
}

National Cancer Institute

\section{Source}

National Cancer Institute. Dermal Fibroma. NCI Thesaurus. Code C6484.

A benign neoplasm arising from the dermis. It is characterized by the presence of spindle-shaped fibroblasts. 